\title{
Magnitude of virologic failure and associated factors among adult patients on antiretroviral therapy at Debre Markos Referral Hospital, Northwest Ethiopia, 2018
}

\author{
Addisu Abebaw \\ Mekuanint Taddele \\ Girma Alem \\ Tesfa Birlew ( $\square$ tesfabirlew@yahoo.com ) \\ Debre Markos University College of Health Science \\ sileshi Berihun
}

Research

Keywords: HIV, virological failure, ART, Ethiopia

Posted Date: January 15th, 2020

DOI: https://doi.org/10.21203/rs.2.20845/v1

License: () (i) This work is licensed under a Creative Commons Attribution 4.0 International License. Read Full License 


\section{Abstract}

Background : Viral load monitoring is used as an important marker for diagnosing early treatment failure in patients with HIV infection/AIDS. Ethiopia has started targeted viral load monitoring recently. However, factors leading to virological failure are not well understood. The aim of this study is to assess magnitude of virologic failure and associated factors among adult patient on ART at Debre Markos Referral Hospital, North West Ethiopia.

Methods : Cross sectional study was conducted on 304 participants who had started first line HAAR. Data were collected from patients' chart starting from ART commencement and face to face interview using semi structured questionnaire. Viral load from separated plasma were analyzed according to protocols. The collected data were analyzed using SPSS version 20. Binary and multiple logistic regression models were fitted to identify factors associated with virological failure among adult patient on ART and to control confounding effect. The results were presented as odds ratio (OR) with $95 \%$ confidence intervals. Independent associations were considered with $p<0.05$.

Results: Magnitude of virological failure was 10.5\%. Lower income, $(A O R=3.5,95 \% \mathrm{Cl}=1.2-10.5, \mathrm{P}=0.024)$, lack of social support $(\mathrm{AOR}=2.9,95 \% \mathrm{Cl}=1.01-8.2, \mathrm{P}=0.024)$, Interruption of $\mathrm{ART}$, $(\mathrm{AOR}=3.5,95 \% \mathrm{Cl}=1.01$ $-12.1, P=0.046)$, drug adherence $(A O R=3.6,95 \% \mathrm{Cl}=1.1-11.3, P=0.028)$, non-working functional status $(A O R=3.5,95 \% \mathrm{Cl}=1.2-9.7, \mathrm{P}=0.018), \mathrm{WHO}$ stage III or IV (AOR $=2.9,95 \% \mathrm{Cl}=1.01-8.0, \mathrm{P}=0.040), \mathrm{CD} 4$ count $<200$ cells $/ \mathrm{ml}(\mathrm{AOR}=3.0,95 \% \mathrm{Cl}=1.1-8.0, \mathrm{P}=0.031)$ and $\mathrm{TB}$ co-infection $(\mathrm{AOR}=3.7,95 \% \mathrm{Cl}=1.2-$ $11.3, P=0.018)$ were significantly associated with virological failure.

Conclusions and recommendations : The prevalence of virologic failure was high. Lower income, lack of social support, interruption of ART, drug non-adherence, baseline non-working functional status, WHO stage, CD4 count $<200 \mathrm{cells} / \mathrm{ml}$ and TB co-infection Conducting faith healing, TB co infection, WHO stage III and IV, adherence, and income were determinants of virologic failure. Therefore early identification of associated factors and monitoring of virologic failure has to be strengthened to benefit patients to prevent from further complication. Keywords : HIV, virological failure, ART, Ethiopia

\section{Background}

Human immunodeficiency virus(HIV) is responsible for a worldwide pandemic, and it is the cause of acquired immune deficiency syndrome (AIDS)[1]. Antiretroviral (ARV) drugs refer to the medicines used to treat HIV whereas antiretroviral therapy (ART) refers to the use of a combination of three or more ARV drugs for treating HIV infection synonym with Higlhy active antiretroviral therapy (HAART) [2]. High viral load (virological failure) is defined by a persistently detectable viral load more than 1000 copies $/ \mathrm{ml}$ after at least 6 months of ART initiation[3].

Clinical failure is defined as any WHO stage III or IV illness in the past 12 months. Immunological failure is defined as current CD4 cell count less than CD4 cell count at time of ART initiation or Persistent CD 4 levels below 100 cells $/ \mathrm{mm} 3$ 
Treatment failure is when an antiretroviral regimen is unable to control HIV infection. which can be clinical failure, immunologic failure, virologic failure, or any combination of the three[4].

In 2013 the WHO recommended routine annual viral load monitoring (VLM) for all patients on ART, as the most accurate measure of treatment response. An elevated VL (> $1000 \mathrm{copies} / \mathrm{ml}$ ) in a patient who has been on ART for at least six months can indicate either therapeutic failure due to antiretroviral resistance, and / or poor adherence to treatment[3,5].According to the viral load testing principle in Ethiopia, the three main reasons for viral load testing are: 1 ) routine testing; 2) suspected failure testing, and 3) repeat viral load testing after suspected treatment failure for patients who were virologically non-suppressed on first time testing and underwent enhanced adherence support for 3 months and then repeat three to 6 months before switching to second line drug[6].

Since the introduction of combination drug regimens to treat human immunodeficiency virus infection, known as highly active antiretroviral therapy (HAART), the rates of HIV-related morbidity and mortality have been markedly reduced[7]. However, the presence of antiretroviral drug resistance mutations in the infecting viruses may decrease the effectiveness of antiretroviral treatment because the mutations reduce the chances of full viral suppression[8]. Antiretroviral therapy began in Ethiopia in 2003 and free ART was launched in 2005An estimated 769,500 Ethiopians are currently living with HIV, of whom all require ART and 392086 are currently taking the treatment. To address this problem, the Government of Ethiopia issued the first ART guidelines in 2003, revised in 2005 and 2008 to facilitate a rapid scale up of the service. The need for universal access to care and treatment is the global and national agenda. In view of this adopting the new recommendation of test and start and differentiated care model (appointment spacing model)[9] .

There is indisputable success over the past twenty years in reducing HIV associated morbidity, mortality, transmission, stigma and improving the quality of life of people living with HIV[8]. But still investing and ensuring the sustainability of a viral load monitoring model must be a priority to detect early treatment failure[10]. Priority setting and health system reforms to manage HIV as a chronic disease must be upheld in government agenda[5]. The World Health Organization (WHO) cites poor access to services, complex drug regimens, pregnancy, mental health disorders, substance abuse, weak social support as major barriers to adherence [3].

The latest UNAIDS data, covering 160 countries, shows the last two years the number of people living with HIV on antiretroviral therapy has increased by about a third, reaching 17.0 million people, since the first global treatment target was set in 2003 , annual AIDS-related deaths have decreased by $43 \%$. In the world's most affected region Africa, the number of people on treatment has more than doubled since 2010. AIDS related deaths in the region have decreased by 36\% since 2010[11]. In 2015 there were 2.1 million new HIV infections worldwide, adding up to a total of 36.7 million people living with HIV. Number of people living with HIV on antiretroviral therapy, global, 7.5 million in 2010, 9.1 million in2011, 10.9 million2012, 12.9 million2013, 15.0 million in 2014, and 17.0 million in2015 shows ladder fashion increasing globally putting global burden in the world particularly in eastern Africa according to UNAIDS 2016 estimates.

In 2014, the Joint United Nations Program on HIV/AIDS (UNAIDS) and partners launched the3 90-90-90 targets; the aim was to diagnose $90 \%$ of all HIV-positive persons, provide antiretroviral therapy for $90 \%$ of those diagnosed, and achieve viral suppression for $90 \%$ of those treated by 2020 [8]. In 2014/2015, of the 36.9 million 
of people with HIV globally, only $54 \%$ were diagnosed, $41 \%$ were on ART and $32 \%$ were virally suppressed i.e. virological failure 68 percent, demonstrating that we are still very far from achieving the three 90-90-90 targets[12]. The lowest achievement rates were in low income and middle income countries [5].This is estimated to result in $73 \%$ of people with HIV achieving viral suppression, a crucial step in ending the AIDS epidemic by 2030. However, 36.9 million people are living with HIV today and about 2.1 million new infections were recorded in 2015. Early placement of patients on combined ART and achievement of viral load suppression reduces mortality and HIV transmission and improves quality of life[13].

Adequately highlighted the gap in HIV diagnosis and provision of ART, which may be unattainable under the ambitious, UNAIDS 90-90-90 targets given the current trends[12]. Achieving the United Nations Program on HIV/AIDS (UNAIDS) 90-90-90 targets will require a viral load-informed care to ensure optimal HIV clinical follow-up and resistance systematic analysis of national HIV treatment cascades from 69 countries shows none of the countries had met the 3,90targets[14]. They found that diagnosis $90 \%$ of all HIV-positive people diagnosed ranged from $87 \%$ (the Netherlands) to $11 \%$ (Yemen). Treatment coverage $81 \%$ of all HIV-positive people on ART) ranged from $71 \%$ (Switzerland) to 3\% (Afghanistan). Viral suppression $73 \%$ of all HIV-positive people virally suppressed was between 68\% (Switzerland) and 7\% (China)[13] .In 2014/2015, of the 36.9 million of people with HIV globally, only $54 \%$ were diagnosed, $41 \%$ were on ART and $32 \%$ were virally suppressed, demonstrating that we are still very far from achieving the 90-90-90 targets. The lowest achievement rates were in low income and middle income countries [13]

Early detection of treatment failure, adherence counseling and appropriate switching to second-line therapy are key strengths of a viral load monitored model[15].

Identified gaps: Viral load monitoring has become the standard of care for monitoring the success of treatment and diagnosing early treatment failure of ART and has been explicitly recommended, when available, by the WHO since 2010.But in our settings in which there is no access to viral load testing, clinical monitoring alone or a combination of clinical and immunologic monitoring is used to assess response to ART and determine treatment failure which is late after many complication occur. The development of drug-resistant virus strains can be another threat if this virus starts to transmit in the population. Early detection of treatment failure is crucial to sustain the effectiveness of the first-line therapy by doing as recommended by WHO. But still there is no study is conducted in the study area by testing clients VL to identify between the two factors. Because these technologies are expensive and introduced to our country recently so determining their VL after 6 month of ART initiation, proper initiation will show virologic failure and these study will identify factors associated with virologic failure.

\section{Methods}

Study area, setting and period

The study was conducted at Debre Markos Referral Hospital which is located $300 \mathrm{~km}$ and $265 \mathrm{~km}$ away from the capital city of Ethiopia: Addis Ababa and the Amhara regional city; Bihar Dar respectively. The major Health services provided in the hospital are outpatient, Inpatient and Emergency service. And in outpatient department services such as antiretroviral treatment, voluntary counseling and testing, mental health service, dental health service, radiology health service, laboratory service, emergency service, pharmacy service, cervical cancer 
screening, reproductive health training, There are five Inpatient wards (Gynecological \&Obstetric, Surgical, Medical, Pediatric and Eye unit) with 189 Hospital beds. There are 9 senior physicians, 24 general practitioners, 222 BSC and clinical nurses and other different professionals. The laboratory staffs are 31 (technicians, technologist and MSC in microbiology and parasitology) are highly qualified and the hospitals are well equipped with modern laboratory machine like viral load machine and FMOH select DMRH as one of the 20 viral load monitoring site which is expected to serve as referring site to determine viral load for all ART site in east Gojjam zone and partial west Gojjam .The study was conducted from February 8-May07/05/2018.

Study Design and population

Facility based cross sectional study design was conducted from February8-May07/2018. The source population was all adult PLHIV on Highly Active Antiretroviral Treatment registered and following their treatment in Debre Markos referral Hospital (DMRH) whilst the study population was adult PLHIV $\geq 15$ years old who are taking HAART for $\geq 6$ month in DMRH who have follow up during study period that can fulfill the inclusion criteria

Sample size determination and sampling technique

The sample size is determined $p=$ prevalence from previous studies of virologic failure, $10.7 \%$ in Feleg Hiwot referral hospital(30) and immunologic failure in DMRH is $21 \%$,by taking virologic failure $10.7 \%(0.017)$ giving any particular out come to be with $5 \%$ marginal error and $95 \%$ confidence interval of certainty (alpha $=0.05$ ). The sample size will be estimated based on single population proportion (p). The formula:

$n=(Z a / 2)^{2} P(1-P)$

$(d)^{2}$

Where: $\mathrm{n}=$ Sample size $\mathrm{z}=$ critical value $1.96, \mathrm{p}=$ prevalence of virologic failure rate $10 \% \mathrm{~d}=$ precision (marginal error $)=0.05$ Thus the sample size is $n=(1.96) 2 \times 0.1(1-0.1) 0.0025=152,15.4+152$ With $10 \%$ non response rate the total sample size will be 167 .

All adult client age 15 years and over, HIV infected, continuing on ART for more than 6 month, and returning to clinic for a regular follow-up visit during study period. Simple random sampling method was used with lottery method from appointment registration book. Interview for most of the data and document review for clinical characteristics of patient and blood sample was drawn to determine VL in ART clinic before medication refill by having consent from client (Table 1). 
Table 1

Sample size determination for the study of magnitude of virological failure and associated factors among adults on antiretroviral therapy in Debre Markos referral hospital, northwest, Ethiopia, in 2018

\begin{tabular}{|c|c|c|c|c|c|c|c|c|c|}
\hline S.no. & $\begin{array}{l}\text { Major } \\
\text { significant } \\
\text { Predictor }\end{array}$ & $\mathrm{Cl}$ & Power & $\begin{array}{l}\text { Proportion } \\
\text { of VF } \\
\text { among } \\
\text { exposed }\end{array}$ & $\begin{array}{l}\text { Proportion } \\
\text { of VF } \\
\text { Non } \\
\text { exposed }\end{array}$ & $\begin{array}{l}\text { Control } \\
\text { to case } \\
\text { ratio }\end{array}$ & OR & $\begin{array}{l}\text { None } \\
\text { response } \\
\text { rate }\end{array}$ & $\begin{array}{l}\text { Sample } \\
\text { size } \\
\text { required }\end{array}$ \\
\hline 1 & $\begin{array}{l}\text { functional } \\
\text { status }\end{array}$ & $95 \%$ & $80 \%$ & $24.7 \%$ & $5.1 \%$ & $1 \otimes 1$ & $6.1 \%$ & $10 \%$ & 187 \\
\hline 2 & $\begin{array}{l}\text { Faith } \\
\text { healing }\end{array}$ & $95 \%$ & $80 \%$ & $28.7 \%$ & $5.5 \%$ & $1 \otimes 1$ & 6.9 & $10 \%$ & 108 \\
\hline 3 & $\begin{array}{l}\text { Base line } \\
\text { CD4 count }\end{array}$ & $95 \%$ & $80 \%$ & $19.6 \%$ & $7.4 \%$ & $1 \otimes 1$ & 3.05 & $10 \%$ & 304 \\
\hline 4 & $\begin{array}{l}\text { Medication } \\
\text { dosage }\end{array}$ & $95 \%$ & $80 \%$ & $23.8 \%$ & $7.2 \%$ & $1 \otimes 1$ & 4.02 & $10 \%$ & 189 \\
\hline
\end{tabular}

Operational definition

High viral load: HIV RNA > 1000 copies/ml. Alcoholism: is defined as drinking more than five alcoholic beverages on at least one occasion within the past 30 days. Substance use: is defined as persons reporting smoking, chat chewing and shisha in the last 30 day. Lack of social support: is lack of social support during illness to take to health facility. Lack of disclosure: is defined as lack of telling to people due to fear of negative consequences. ART interruption:' is defined as a treatment interruption for at least 1 week during the previous 6 months. Adult: Those patients with age 15 or more. Missed dose: missing one or more doses in the previous month.

Data Collection Tools

An adapted semi structured questionnaire was prepared in English and translated into Amharic, which is taken from federal $\mathrm{MOH}$ adherence assessment tool and viral load extraction tool from other published research [22].

Interviews were conducted from client coming to follow up in a private setting at the ART clinic before medication refill. In the survey, an interviewer-administrated questionnaire was conducted to collect demographic data, substance use and psychosocial factors. socio economic and behavioral factors, drug related characteristics of clients but Clinical characteristics of HIV patient data were collected from patient chart adherences was assessed by patient self report based on pills count as good if take $>95 \%$,poor if $<95 \%$ taken. After completing the questionnaire, patients underwent routine follow-up and blood work with the addition of a single viral load test $5 \mathrm{ml}$ of whole blood was drawn and preserved in an EDTA tube, stored at appropriate temperatures for processing and tested for viral load by molecular machine(rochi).

Data Quality Assurance

The validity of the questionnaires was assured by proper designing and also pre-testing the questionnaire in $5 \%$ (15) of respondents other than those involved in the actual study in Debre markos health center. One days 
training was given to data collectors and supervisors at Debre Markos referal hospital. Questionnaire was checked for completeness on a daily basis by immediate supervisors. After checking all questionnaires for consistency and completeness the supervisors were submit the filled questionnaire to the principal investigator. Data collection and supervision was carried out by qualified personnel, four nurses who were not working in the study site were recruited and trained for data collection and they had at least diploma in status and the supervisors was BSC holder in health .

Data processing, analysis and interpretation

All responses to the survey questionnaires or collected data was retranslated against the original English version and entered into Epi Data version 3.1 and analyzed by SPSS version 20. Data cleaning were made manually by removing missing/conflicting ideas and responses to questions about relevant information. Recoding and re-categorizing was made for relevant variables. Frequencies and summary statistics were used

to describe the study population in relation to socio-demographic and other relevant variables. The strength of association between dependent and independent variables was assessed using adjusted odds ratio with $95 \%$ confidence interval. Bivariate and multivariate logistic regressions was performed to assess statistical association between dependent and independent variable.. Then, variables, which showed statistical association with p-value of less than 0.25 on bivariate analysis, were candidates for the multivariate logistic regression model. In the multiple logistic regression models significant association was declared at $p$-value < 0.05. Finally data was interpreted with the existed data by referring to literature reviews.

\section{Result}

\section{1}

Socio-demographic characteristics

A total of 304 study participants were included in the study which give a response rate of $100.0 \%$. At baseline, the mean age of the study subjects was 37.3 years $\pm S D,(S D=10.6)$. The age was ranged from 16 to 72 years. One hundred seventy three 179 (58.9\%) were females. Regarding educational status 103 (33.9\%) of the respondents completed college and above while 70 (23.0\%) were not attended formal education. Majority, 243 (79.9\%), of the respondents reside in rural residential area. Larger proportion of the respondents $100(32.9 \%)$ earn a monthly income of 1,500-3,199 ETB followed by $29.6 \%$ and $20.5 \%$ earning monthly income of $\geq 3200$ ETB and < 1000 ETB respectively. These and the rest socio-economic and demographic characteristics of the respondents have been presented in Table 2. 
Table 2

Socio-demographic characteristics of adult patient on ART at Debre Markos Referral Hospital, North West Ethiopia, 2018

\begin{tabular}{|c|c|c|}
\hline Variable & No & $\%$ \\
\hline \multicolumn{3}{|l|}{ Age (year) } \\
\hline $15-29$ & 67 & 22.0 \\
\hline $30-35$ & 77 & 25.3 \\
\hline $36-41$ & 79 & 26.0 \\
\hline$\geq 42$ & 81 & 26.6 \\
\hline \multicolumn{3}{|l|}{ Sex } \\
\hline Male & 125 & 41.1 \\
\hline Female & 179 & 58.9 \\
\hline \multicolumn{3}{|l|}{ Marital status } \\
\hline Single & 48 & 15.8 \\
\hline Married & 154 & 50.7 \\
\hline Divorced & 63 & 20.7 \\
\hline Widowed and separated & 39 & 12.8 \\
\hline \multicolumn{3}{|l|}{ Educational status } \\
\hline No formal education & 70 & 23.0 \\
\hline Literate & 234 & 77.0 \\
\hline \multicolumn{3}{|l|}{ Occupation } \\
\hline House wife & 83 & 27.3 \\
\hline Government employee & 75 & 24.7 \\
\hline Daily laborer & 46 & 15.1 \\
\hline Driver & 32 & 10.5 \\
\hline Others & 68 & 22.4 \\
\hline \multicolumn{3}{|l|}{ Residence } \\
\hline Rural & 61 & 20.1 \\
\hline Urban & 243 & 79.9 \\
\hline
\end{tabular}




\begin{tabular}{|lcc|}
\hline Variable & No & $\%$ \\
\hline$<10 \mathrm{Km}$ & 181 & 59.5 \\
\hline$\geq 10 \mathrm{Km}$ & 123 & 40.5 \\
\hline Monthly income & & \\
\hline$<1500 \mathrm{ETB}$ & 114 & 37.5 \\
\hline$\geq 1500 \mathrm{ETB}$ & 190 & 62.5 \\
\hline
\end{tabular}

1.2

Psycho-social related characteristics

Majority, 217 (71.4\%), of study participants live with their own family whereas 61 (20.1\%) and 26(8.6\%) live alone and with their parents. One hundred thirty seven $(45.1 \%)$ of the study participant's regular sexual partners were HIV positive, $46(15.1 \%)$ of the participants were discordant in their HIV status with their regular sexual partners and the rest had sexual partners with unknown HIV status. Ninety six (31.6\%) of the study participants disclosed their status to their family, while 21(6.9\%) respondent's families were non-supportive or kept him/her from taking ARTs. Lack of food was a problem for $58(19.1 \%)$ of the respondents which hinder them to take ART dose. Eighteen (5.9\%) of participant did not belief on the efficacy of the drug they have taken. From the total study participants $79(26.0 \%)$ experienced discrimination, $83(27.3 \%)$ lack social support and $55(18.1 \%)$ lack emotional support (Table 3). 
Table 3

Psycho-social and substance use related characteristics of adult patient on ART at Debre Markos Referral Hospital, North West Ethiopia, 2018

\begin{tabular}{|c|c|c|}
\hline Variable & No & $\%$ \\
\hline \multicolumn{3}{|l|}{ Live with } \\
\hline Alone & 61 & 20.1 \\
\hline Family & 217 & 71.4 \\
\hline Parents & 26 & 8.6 \\
\hline \multicolumn{3}{|c|}{ HIV status of regular sex partner } \\
\hline Negative & 46 & 15.1 \\
\hline Positive & 137 & 45.1 \\
\hline Unknown & 121 & 39.8 \\
\hline \multicolumn{3}{|c|}{ Disclosing HIV status to family } \\
\hline Yes & 96 & 31.6 \\
\hline No & 208 & 68.4 \\
\hline \multicolumn{3}{|c|}{ Belief in efficiency of medication } \\
\hline Yes & 286 & 94.1 \\
\hline No & 18 & 5.9 \\
\hline \multicolumn{3}{|c|}{ Discrimination } \\
\hline Yes & 79 & 26.0 \\
\hline No & 225 & 74.0 \\
\hline \multicolumn{3}{|c|}{ Lack of social support } \\
\hline Yes & 83 & 27.3 \\
\hline No & 221 & 72.7 \\
\hline \multicolumn{3}{|c|}{ Emotional support } \\
\hline Yes & 249 & 81.9 \\
\hline No & 55 & 18.1 \\
\hline \multicolumn{3}{|c|}{ Family been non-supportive or kept him/her from taking ART } \\
\hline Yes & 21 & 6.9 \\
\hline No & 283 & 93.1 \\
\hline
\end{tabular}




\begin{tabular}{|lcc|}
\hline Variable & No & $\%$ \\
\hline Yes & 58 & 19.1 \\
\hline No & 246 & 80.9 \\
\hline Felt sad or hopelessness for 2 weeks & & \\
\hline Yes & 26 & 8.6 \\
\hline No & 278 & 91.4 \\
\hline Presence of loss of interest for 2 months & & \\
\hline Yes & 26 & 8.6 \\
\hline No & 278 & 91.4 \\
\hline History of substance use & & \\
\hline Yes & 28 & 9.2 \\
\hline No & 276 & 90.8 \\
\hline
\end{tabular}

Twenty eight (9.2\%) of the respondents had taken at least one type of substance (drunk alcohol, chewed khat or smoked tobacco) in the last one month; 28(9.2\%), 15 (4.9\%) and 5(1.6\%) were drank alcohol, chewed khat and smoked tobacco in the last month respectively. Moreover, All of the participants reported substance use drank alcohol, 13 (46.4\%) of them drink alcohol and chewed khat and 3 (10.7\%) of them used khat, tobacco and alcohol.

\section{3}

Drug related characteristics of adult patient on antiretroviral therapy

More than half $(54.6 \%)$ of the study participants were on 1E (TDF + 3TC + EFV) at baseline. 1C $(A Z T+3 T C+$ NVP). 1D (AZT + 3TC + EFV) and 1B (d4T + 3TC + EFV) were the initial ART regimens for 53(17.4\%) 44(14.5\%) and $34(11.2 \%)$ of the respondents respectively. Most of the participants, $214(70.4 \%)$, taken ART for more than 36 months; the median duration of treatment was 42.0 months (interquartile range [IQR], 18.0-60.2). These and the rest drug related characteristics of the respondents have been detailed in Table 5. 
Table 5

Medication related behavioral characteristics of adult patient on ART at Debre Markos Referral Hospital, North West Ethiopia, 2018

\begin{tabular}{|c|c|c|}
\hline Variable & No & $\%$ \\
\hline \multicolumn{3}{|c|}{ Time on ART (in months) } \\
\hline$<36$ Months & 90 & 29.6 \\
\hline 36-72 Months & 74 & 24.3 \\
\hline$>72$ Months & 140 & 46.1 \\
\hline \multicolumn{3}{|c|}{ Interrupted care follow up/medication refill since started ART } \\
\hline Yes & 56 & 18.4 \\
\hline No & 248 & 81.6 \\
\hline \multicolumn{3}{|c|}{ Discontinued ART to take other traditional herbal medicine, holy water } \\
\hline Yes & 64 & 21.1 \\
\hline No & 240 & 78.9 \\
\hline \multicolumn{3}{|c|}{ Missed ART doses in the past since started } \\
\hline Yes & 77 & 25.3 \\
\hline No & 227 & 74.7 \\
\hline \multicolumn{3}{|c|}{ Forgetting to take ART doses at scheduled time } \\
\hline Yes & 73 & 24.0 \\
\hline No & 231 & 76.0 \\
\hline \multicolumn{3}{|l|}{ Drug adherence } \\
\hline Good & 139 & 45.7 \\
\hline Poor & 165 & 54.3 \\
\hline
\end{tabular}

1.4

Medication related behavioral characteristics

Fifty six (18.4\%) of the respondents had discontinued their interrupted care follow up/medication refill since started ART. About 197(64.8\%) of the respondents missed their ART dose indeed in the past since started and about $24 \%$ experienced forgetting to take ART doses at scheduled time. Furthermore, 64(21.1\%) of the study participants discontinued ART drugs to take other traditional herbal medicine and holy water About $45.4 \%$ of the respondents had good adherence (taken > 95\% of drugs) to their treatment; while $95(23.4 \%)$ respondents had poor adherence (Table 4). 
Table 4

Drug related characteristics of adult patient on ART at Debre Markos Referral Hospital, North West

Ethiopia, 2018

\begin{tabular}{|c|c|c|}
\hline Variable & No & $\%$ \\
\hline \multicolumn{3}{|l|}{ First line drug regimen } \\
\hline $1 \mathrm{~A}(\mathrm{~d} 4 \mathrm{~T}+3 \mathrm{TC}+\mathrm{NVP})$ & 3 & 1.0 \\
\hline $1 \mathrm{~B}(\mathrm{~d} 4 \mathrm{~T}+3 \mathrm{TC}+\mathrm{EFV})$ & 34 & 11.2 \\
\hline $1 \mathrm{C}(\mathrm{AZT}+3 \mathrm{TC}+\mathrm{NVP})$ & 53 & 17.4 \\
\hline 1D (AZT + 3TC + EFV) & 44 & 14.5 \\
\hline $1 E(T D F+3 T C+E F V)$ & 166 & 54.6 \\
\hline $1 F(T D F+3 T C+N V P)$ & 4 & 1.3 \\
\hline \multicolumn{3}{|c|}{ Time on ART (in months) } \\
\hline$<36$ Months & 90 & 29.6 \\
\hline 36-72 Months & 74 & 24.3 \\
\hline > 72 Months & 140 & 46.1 \\
\hline \multicolumn{3}{|l|}{ ART doses taken per day } \\
\hline Once & 197 & 64.8 \\
\hline Twice & 107 & 35.2 \\
\hline \multicolumn{3}{|c|}{ Presence of reported side effects } \\
\hline Yes & 77 & 25.3 \\
\hline No & 227 & 74.7 \\
\hline \multicolumn{3}{|l|}{ Regimen change } \\
\hline Yes & 94 & 30.9 \\
\hline No & 210 & 69.1 \\
\hline \multicolumn{3}{|l|}{ Regimen stopped } \\
\hline Yes & 20 & 6.6 \\
\hline No & 284 & 93.4 \\
\hline
\end{tabular}

1.5

Clinical characteristics of adult patient on antiretroviral therapy 
Among the participants, 196 (64.5) were classified as working and the rest were ambulatory and bed reddened in accordance their magnitude at baseline which summed to give the proportion of non-working participants (35.5\%) (Fig. 4).

Nearly two third, 196 (64.5\%), of the participants started treatment at stage 1 and 2 of WHO disease classification; the rest 51 (16.8\%) and $56(18.4 \%)$ were suffered WHO stages 3 and 4 conditions respectively at the time of ART initiation (Fig. 5).

The median baseline CD 4 cell count was $344.5 \mathrm{cells} / \mathrm{ml}(\mathrm{IQR}=582-213)$; the proportions of participants with baseline CD 4 count of $<200$ cells $/ \mathrm{ml}, 200-500$ cells $/ \mathrm{ml}>500$ cells $/ \mathrm{ml}$ were $23.7 \%, 42.4 \%$ and $33.9 \%$, respectively. Moreover, 69 (22.7\%) of the study participants had TB co-infection at the initiation of ART, while $45(14.8 \%)$ of the participants acquired TB after enrollment in ART. In addition $165(54.5 \%)$ of the respondents had opportunistic infection at the time of their ART initiation; 79(52.1\%) of these had more than one opportunistic infection (Table 6).

Table 6

Baseline clinical characteristics of adult patient on ART at Debre Markos Referral Hospital, North West Ethiopia, 2018

\begin{tabular}{|llc|}
\hline Variable & No & $\%$ \\
\hline CD4 count cells/ml & & \\
\hline$<200$ & 72 & 23.7 \\
\hline $200-500$ & 129 & 42.4 \\
\hline$>500$ & 103 & 33.9 \\
\hline TB co-infection at initiation of ART & & \\
\hline Yes & 69 & 22.7 \\
\hline No & 235 & 77.3 \\
\hline TB development after ART initiation & & \\
\hline Yes & 45 & 14.8 \\
\hline No & 259 & 85.2 \\
\hline Opportunistic infection other than TB at initiation of ART & & \\
\hline Yes & 165 & 54.3 \\
\hline No & 139 & 45.7 \\
\hline No of opportunistic infection ( $n=165)$ & & \\
\hline One Ol & 86 & 52.1 \\
\hline More than one Ols & 79 & 47.9 \\
\hline
\end{tabular}


Candidiasis, herpes zoster, recurrent pneumonia and diarrhea (> 1 month) were the four most frequent opportunistic infections developed by $54(32.7 \%), 49(29.7 \%), 48(29.1 \%)$ and $36(21.8 \%)$ of the respondents who had opportunistic infection respectively (Fig. 6)

The median viral load was 57.5 (IQR: 127.8-43.0). Majority of the study participants, $272(89.5 \%)$, had viral load of $<1000$ RNA copies/ml and the rest 32 had viral load of $\geq 1000$ RNA copies/ml indicating the magnitude of virological failure to be $10.5 \%$ (Fig. 7).

1.6

Determinant factors of virologic failure among of adult patient on ART

The bivariate logistic regression modeling result revealed that sex, educational status and average monthly income of the respondents were socio-demographic factors that had statistically significant ( $p$-value less than 0.05 ) association with antiretroviral virological failure. The bivariate logistic regression modeling result also showed that, lack of social support, discrimination, feeling sad or hopelessness, loss of interest in most things like hobbies, work, or activates that usually give pleasure, family been non-supportive taking ARTs and substance use were psycho-social related factors significantly associated with virological failure. The result showed that none of the drug related factors had statistically significant relationship with virological failure. From medication related behavioral factors of the respondent's discontinuation /interruption of care follow up/medication, presence of missed ART doses in the past 30 day and discontinuation /interruption of ART to take other traditional herbal medicine, holy water and drug adherence were significantly associated with the dependent variable. Significant associations were also found between virological failure and baseline clinical characteristics of the respondents, namely: baseline functional status, baseline WHO clinical stage, baseline CD4 count and baseline TB co-infection (Anex-4 No 2).

As summarized in the following table (Table 7), multivariate logistic regression model was fitted to assess the independent effect of each of the factor found to be associated in the bivariate analysis. Average monthly income, lack of social support, discontinuation /interruption of ART to take other traditional herbal medicine, holy water etc..., drug adherence, baseline functional status, baseline WHO clinical stage, baseline CD 4 count and baseline TB co-infection were remained to be independent determinant factors for virologic failure among adult patient on ART. 
Table 7

Factors associated with virologic failure among of adult patient on antiretroviral therapy at Debre Markos Referral Hospital, North West Ethiopia, 2018

\begin{tabular}{|c|c|c|c|c|c|c|}
\hline \multirow[t]{3}{*}{ Variables } & \multicolumn{4}{|c|}{ Virologic failure } & \multirow{3}{*}{$\begin{array}{l}\text { COR } \\
(95 \% \mathrm{Cl})\end{array}$} & \multirow{3}{*}{$\begin{array}{l}\text { AOR } \\
(95 \% \mathrm{Cl})\end{array}$} \\
\hline & \multicolumn{2}{|l|}{ Yes } & \multicolumn{2}{|l|}{ No } & & \\
\hline & No & $\%$ & No & $\%$ & & \\
\hline \multicolumn{7}{|l|}{ Monthly income (ETB) } \\
\hline$<1500$ ETB & 12 & 18.5 & 53 & 81.5 & $\begin{array}{l}3.8 \\
(1.5- \\
6.7)^{\star}\end{array}$ & $\begin{array}{l}3.5 \\
(1.2- \\
10.5)^{\star}\end{array}$ \\
\hline$\geq 1500$ and above ETB & 5 & 5.6 & 85 & 94.4 & 1 & 1 \\
\hline \multicolumn{7}{|l|}{ Lack of social support } \\
\hline Yes & 16 & 19.3 & 67 & 80.7 & $\begin{array}{l}3.1 \\
(1.5- \\
6.5)^{\star}\end{array}$ & $\begin{array}{l}2.9 \\
(1.01- \\
8.2)^{\star}\end{array}$ \\
\hline No & 16 & 7.2 & 205 & 92.8 & 1 & 1 \\
\hline \multicolumn{7}{|c|}{$\begin{array}{l}\text { Discontinued ARVs to take other traditional herbal } \\
\text { medicine, holy water }\end{array}$} \\
\hline Yes & 18 & 28.1 & 46 & 71.9 & $\begin{array}{l}6.3 \\
(2.9- \\
13.6)^{\star \star}\end{array}$ & $\begin{array}{l}3.5 \\
(1.01- \\
12.1)^{\star}\end{array}$ \\
\hline No & 14 & 5.8 & 226 & 94.2 & 1 & 1 \\
\hline \multicolumn{7}{|l|}{ Drug adherence } \\
\hline Good & 9 & 6.5 & 130 & 93.5 & 1 & 1 \\
\hline Poor & 23 & 13.9 & 142 & 86.1 & $\begin{array}{l}2.3 \\
(1.01- \\
5.2)^{\star}\end{array}$ & $\begin{array}{l}3.6 \\
(1.1- \\
11.3)^{\star}\end{array}$ \\
\hline \multicolumn{7}{|c|}{ Baseline functional status } \\
\hline Working & 16 & 8.2 & 180 & 91.8 & 1 & 1 \\
\hline Non-working & 16 & 14.8 & 92 & 85.2 & $\begin{array}{l}2.0 \\
(1.01- \\
4.1)^{\star}\end{array}$ & $\begin{array}{l}3.5 \\
(1.2- \\
9.7)^{\star}\end{array}$ \\
\hline \multicolumn{7}{|l|}{ WHO stage at baseline } \\
\hline Stage1/2 & 12 & 6.1 & 184 & 93.9 & 1 & 1 \\
\hline
\end{tabular}

* Association is significant at the 0.05 level. ** Association is significant at less than 0.001 level 


\begin{tabular}{|c|c|c|c|c|c|c|}
\hline \multirow[t]{3}{*}{ Variables } & \multicolumn{4}{|c|}{ Virologic failure } & \multirow{3}{*}{$\begin{array}{l}\text { COR } \\
(95 \% \mathrm{Cl})\end{array}$} & \multirow{3}{*}{$\begin{array}{l}\text { AOR } \\
(95 \% \mathrm{Cl})\end{array}$} \\
\hline & \multicolumn{2}{|l|}{ Yes } & \multicolumn{2}{|l|}{ No } & & \\
\hline & No & $\%$ & No & $\%$ & & \\
\hline Stage $3 / 4$ & 20 & 18.5 & 88 & 81.5 & $\begin{array}{l}3.5 \\
(1.6- \\
7.5)^{\star}\end{array}$ & $\begin{array}{l}2.9 \\
(1.01- \\
7.9)^{\star}\end{array}$ \\
\hline \multicolumn{7}{|l|}{ CD4 count } \\
\hline$<200$ & 17 & 23.6 & 55 & 76.4 & $\begin{array}{l}4.5 \\
(2.1- \\
9.5)^{\star \star}\end{array}$ & $\begin{array}{l}3.0(1.1- \\
8.0)^{\star}\end{array}$ \\
\hline$\geq 200$ & 15 & 6.5 & 217 & 93.5 & 1 & 1 \\
\hline \multicolumn{7}{|c|}{ TB co-infection at initiation of ART } \\
\hline Yes & 16 & 23.2 & 53 & 76.8 & $\begin{array}{l}4.1 \\
(1.9- \\
8.9)^{\star \star}\end{array}$ & $\begin{array}{l}3.7 \\
(1.2- \\
11.3)^{\star}\end{array}$ \\
\hline No & 16 & 6.8 & 219 & 93.2 & 1 & 1 \\
\hline
\end{tabular}

The multivariate logistic modeling result showed that monthly income was a strong determinant factor for virologic failure; those adult patients on ART who earned a monthly income of less than 1500 ETB were 3.5 times more likely to experience virologic failure as compared with those adult patients that earned a monthly income of $1500 \mathrm{ETB}$ and above $(\mathrm{AOR}=3.5,95 \% \mathrm{Cl}=1.2-10.5, \mathrm{P}=0.024)$. Lack of social support was another important determinant of virologic failure. Patients lacked social support were more likely to experience virologic failure $(\mathrm{AOR}=2.9,95 \% \mathrm{Cl}=1.01-8.2, \mathrm{P}=0.024)$ than their counterparts.

Discontinuation /interruption of ART to take other traditional herbal medicine, holy water etc... and drug adherence were found to be the other statistically significant determinant factors of virologic failure. Compared to those patients who did not interrupted their treatment /ART/, patients who had interrupted ART to take other traditional herbal medicine, holy water etc had 3.5 times higher probability of having virological failure (AOR = $3.5,95 \% \mathrm{Cl}=1.01-12.1, \mathrm{P}=0.046)$. Similarly patients who had not good drug adherence were 3.6 times more likely to experience virological failure than their counterparts $(A O R=3.6,95 \% \mathrm{Cl}=1.1-11.3, \mathrm{P}=0.028)$.

Baseline clinical characteristics of the patients; functioning status, WHO stage, CD4 count and TB co-infection were also strong predictors of virological failure. When compared to working patients at the initiation of ART, the probability of virological failure was 3.5 times higher for patients who were not working due to health problem at the time of ART initiation of $(A O R=3.5,95 \% \mathrm{Cl}=1.2-9.7, \mathrm{P}=0.018)$. Similarly, those patients who started ART at WHO stage 3 or 4 had a 2.9 times higher probability of experiencing virological failure when compared to those who patients started at WHO stage 1 or $2(\mathrm{AOR}=2.9,95 \% \mathrm{Cl}=1.01-8.0, \mathrm{P}=0.040)$. Regarding the baseline CD 4 cell count, those patients with baseline CD 4 count $<200$ cells $/ \mathrm{ml}$ were 3.0 times more likely to have virological failure compared to those patients with CD4 count $\geq 200 \mathrm{cells} / \mathrm{ml}(\mathrm{AOR}=3.0$, 
95\% $\mathrm{Cl}=1.1-8.0, \mathrm{P}=0.031)$. Compared with baseline HIV mono-infected patients, HIV/TB co-infected patients at the initiation of ART had remarkably higher odds of experiencing virologic failure $(\mathrm{AOR}=3.7,95 \% \mathrm{Cl}=1.2-$ 11.3, $P=0.018)$ (Table 7).

\section{Discussion}

The finding of this study showed that the magnitude of virological failure (viral load $\geq 1000 \mathrm{copies} / \mathrm{ml}$ ) was $10.5 \%$. This finding was comparable with studies conducted in Uganda 11\% [26], and it was also in line with studies done in Ethiopia; Tigray (11.5\%) [35], Gondar (11.8\%) [32] and Bahir Dar Feleg Hiwot (10.7\%) [30]. However, the result of the current study, higher virological failure was reported studies done in Kenya 23.7\% [22] and Cameron (23.2\%) [23], 20.6\% [37] and Swaziland 16\% [28]. This difference may be due to differences in definition of virological failure, where plasma viral load 400 copies/ml was used as cut-off point for virological failure $[22,23,37]$. Differences in the inclusion criteria used might also be another possible explanation, i.e., the study participants included in those studies were clinically or immunologically failed and had lower median age (9.5 years old) $[37,38]$. On the other hand, the finding of the current study was higher than studies in Bale (9.3\%) [29], Gondar (4.1\%) [24], Addis Ababa (1.3\%) [41] and Jimma (5.3\%) [36]. It was also lower than a metaanalysis done in Ethiopia that reported overall virological failure of 5.6 [42]. The possible explanation might be due to difference in interventions for optimization of patient's adherence, better treatment outcome and type of regimen given. For instance, nutritional support was given for the study participants [36] which were different from the current study setting. Furthermore, the differences might also be due to the study areas where the residents of these areas can also be with different socio-economic status.

In the current study virological failure was varied by monthly income of the respondents, patients who had had low monthly income were more likely to experience virological failure. In agreement with this finding there is good reason to expect that socio-economic variables should be associated with antiretroviral adherence and living conditions including availability of food which in turn can impact HIV disease activity (including viral replication) [38, 39]. For instance, a study done in Jimma, Ethiopia [36] reported that patients with average family income of middle and highest were more likely to have an overall adherence and ART outcome than the lowest average family income. Likewise a study from India [39] reported that having the economic ability to fulfil their basic needs and to receive their medication had a positive significant association with both ART drug adherence and treatment outcomes [39].

The finding of the current study showed that social support was another determinant factor for virological failure; Patients lacking psychosocial support from family and others exhibited poor virological suppression. This implies that consistent psycho-social support have a positive impact on ART outcomes. In line with this studies done in Uganda [26], Swaziland [38] reported positive social support was associated with relatively good treatment adherence and in turn better viral load reduction. Moreover, WHO's ART guideline recommend behavioral intervention (social support, avoidance of discrimination, depression) to prevent treatment interruption and to control HIV activities/replication and bring better treatment success [3]. Social support, such as someone to help with the tasks of starting to rebuild a life, assistance with cooking and assistance to grow crops, all encouraged ART adherence, prevention of opportunistic infections and reduction of viral replication and finally better treatment outcome [33, 34,39]. Similarly, it has been reported in other study [40] as social 
support was a constant predictor of could virological suppression because it help to avoid risky daily behaviors and activities of the patient.

Interruption medication, specifically interruption of treatment to take other traditional herbal medicine, holy water etc..., was a strong determinant factor of virological failure. In agreement with previous studies conducted in Ethiopia [32, 33, 34], this study identified that those patients who had interrupted their ART medication and use traditional herbal medicine or faith heal (like Holy water) were at a higher risk to developing virological failure than their counterparts. This fining was supported and evidenced by results of the above mentioned studies conducted in Ethiopia. A study done in Gondar [32] showed that individuals who missed 3 doses of ART per month were associated with an increased risk of drug resistance and reduced immunity, this in turn resulted in the loss of the opportunity to suppress viral replication and leads to virological failure.

Poor ART adherence found to have a great impact on the occurrence of HIV treatment failure [3]. It is widely agreed that once treatment is initiated, it should not be interrupted $[3,9,38,44]$. Despite this fact, in the current study the magnitude of poor adherence was about $23.3 \%$ and this poor adherence to ART was found to be an important determinant of virological failure. Patients with poor medication adherence were 3.5 times as likely to develop virological failure as patients with good adherence. This is because low level of antiretroviral in the body owing to the non-adherence is not sufficient to suppress viral replication, hence leads to detection of HIV RNA level in the blood $[3,44]$. Even though, there was differences in adherence measurement, this finding was comparable with findings of studies conducted in Uganda [26], Kenya [22], Swaziland [38], Tigray [35], Gondar [32] and Jimma [36] where poor medication adherence was the main risk factor for virological failure. For example the study done in Gondar reported that patients with poor medication adherence were 16 times more likely to develop virological failure compared with patients with good adherence [32]. In order to explain the effect of adherence on ART viral suppression studies suggested that around $70 \%$ of patients on first-line ART who had a first high viral load will re-suppress following an adherence intervention [44], indicating nonadherence as the reason for the high viral load in the majority of cases.

In agreement with previous studies [32, 35-42], the current study found baseline non-working functional status, low CD4 cell count, advanced WHO clinical stage, and presence of opportunistic infections leads to ART virological failure. Despite this fact, these risk factors are highly interconnected, CD4 cell count is the backbone of immunity construction that helps the human body to protect from the disease and can prevent HIV replication [44]. As patients' immune status becomes compromised, the rate of viral replication increase and the chance of acquiring opportunistic infections is high which leads to advanced stage of the disease.

Consequently, the patient gives more emphasis to the current problem than the chronic HIV, stop taking drugs and interrupt follow-up (poor adherence) which cause HIV treatment failure/virological failure.

Baseline working status of the patents was one of the determinant factor of virologic failure; this study found that the patients who were not able to work (initial non-working functional status, i.e. ambulatory/bedridden) due to health problem had 3.5 times more risk of developing virological failure than patients who were able to work (initial working functional status). This finding was concordant with study done in Ethiopia [35, 41, 43]. This might be due to the fact that those worker patients may have better income that in turn creates opportunity to get better care and support. This finding could also be explained as patients who were unable to work might be in their advanced WHO stage of the disease aggravated from greater immunosuppression (low CD4 count)

Page 19/31 
$[5,13,44]$ or they might be depressed, feel hopelessness which might in turn lead to poor drug adherence then virological or in general treatment failure [37-40]. .

Patients with baseline low CD4 count were more likely to develop virological failure as those with higher CD4 count ( $>200$ cells/mm3). The finding was consistent with those of studies conducted in Uganda [16], Kenya [28], Vietnam [28] and India [28]. It had been evidenced that CD4 count has an inverse relationship with viral replication and load. That is, as patients' immune status becomes compromised (low CD4 count), the rate of viral replication increases compared to their immune-competent counterparts [3, 40,44]. Furthermore, clients with compromised immunity are more vulnerable to different opportunistic infections that sustain the vicious

cycle of immunity and viral replication [44]. On the other hand, low CD4 count might reflect viral replication due to treatment interruption (poor adherence) or resistance $[7,18]$.

In this study TB co-infection at start of ART was founded to be a strong determinant factor of virologic failure. This finding was in line with study conducted in Haiti [19], Cameroon [23] and Uganda [26]. One of the possible explanation for this result might be the fact that the intimate linkage between HIV and Tb might compress the immunity of the patient (including decrease in count of CD4 cells) and enables the progression of HIV disease to advanced stage rapidly and disallowing patients from regular treatment intake and hence lead to virological failure [31, 34].

Even though statistically significant association between virological failure and age, educational status, substance use, duration of ART (time on ART) and presence of other opportunistic infections was reported by a lot of previous studies $[19,23,29,38]$, the result of the current study did not suggest an association between these factors and ART virological failure. The differences in study designs, where some of the previous studies were case-control and cohort study designs; study population (patients in more than one health facility, different sample size, different aged /some include children); and study areas might be possible explanation for the difference between the results of the current and previous studies.

\section{Conclusions}

The magnitude of virological failure among adult HIV patients on ART was high, it was higher than most the findings of studies in the country and even in the region.

Having lower monthly income, lack of social support, interruption of ART to take traditional herbal medicine/Holy water, baseline non-working functional status, baseline advanced (III and IV) WHO stage, baseline CD4 count < 200 cells/ml and baseline TB co-infection were predictors of ART virologic failure among adult HIV patients on ART.

\section{Abbreviations}

AIDS $\quad$ Acquired Immuno Deficiency Syndrome

ART Ante Retroviral Therapy

Page 20/31 


$\begin{array}{ll}\text { DMRH } & \text { Debre Markos Referral Hospital } \\ \text { HAART } & \text { Highly Active Antiretroviral Therapy } \\ \text { HIV } & \text { Human Immunodeficiency Virus } \\ \text { MOH } & \text { Ministry of Health } \\ \text { PLWHIV } & \text { People Living With HIV } \\ \text { PMTCT } & \text { Prevention of Mother-to-Child Transmission of HIV } \\ \text { VL } & \text { Viral Load } \\ \text { VLM } & \text { Viral Load Monitoring } \\ \text { VF } & \text { Virologic Failure } \\ \text { WHO } & \text { World Health Organization }\end{array}$

\section{Declarations}

\section{Ethics approval and consent to participate}

Ethical clearance was obtained from the ethical review committee of Debremarkos University, College of Health Sciences but the committee's reference number and human participant consent not applicable.

\section{Consent for publication}

The information requested does not applicable

\section{Competing interests}

The authors declare that they have no competing interests.

\section{Availability of data and material}

The datasets generated during and/or analyzed during the current study are available from the corresponding author on reasonable request.

\section{Funding}

Debre Markos University contributed all financial need for the research.

\section{Ethical consideration and consent}


Ethical approval and clearance was obtained from Debre Markos University health Science College. Formal letter was received from hospital to review patients' medical charts for data collection. Prior to the interview Verbal consent was obtained from the study participants and parents of age 15-17years old. No identifiers were collected from the clients to ensure their confidentiality.

\section{Author's contributions}

The authors' responsibilities were as follows: A.A participated in the design of the study, performed the data collection and the statistical analysis and served as the lead author of the manuscript. M.T and G.A supervised the study, and ensured quality of the data. TB and SB were involved in writing the manuscript. All authors also highly participated in preparing and revising this final manuscript and approved the final manuscript.

\section{ACKNOWLEDGMENT}

I am very much indebted to my advisors Mr. Girma Alem and Mr. Mekuanint Taddele for their unreserved guidance and support.

I would like to thanks Debre markos University department of public health for giving me a permission to conduct this study at Debremarkos Referral Hospital.

I would like to thank my colleagues, for their constructive comments, suggestions, and supplementary ideas for this thesis development.

Last, but not least, I would like to thank Debremarkos Referal Hospital ART department workers for their help by giving necessary data to do this thesis.

Finally I would like to thank Debremarkos Referal Hospital card room workers for their help by identifying and giving the selected patient's follow up cards.

\section{References}

1. Palella Jr, F.J., et al., Declining morbidity and mortality among patients with advanced human immunodeficiency virus infection. New England Journal of Medicine, 1998. 338(13): p. 853-860.

2. Wat, A., from Wikipedia, the free encyclopedia. 2010.

3. Organization, W.H., Consolidated guidelines on the use of antiretroviral drugs for treating and preventing HIV infection: recommendations for a public health approach. 2016: World Health Organization.

4. Budka, H., et al., HIV-associated disease of the nervous system: review of nomenclature and proposal for neuropathology-based terminology. Brain Pathology, 1991. 1(3): p. 143-152.

5. Bain, L.E., C. Nkoke, and J.J.N. Noubiap, UNAIDS 90-90-90 targets to end the AIDS epidemic by 2020 are not realistic: comment on "Can the UNAIDS 90-90-90 target be achieved? A systematic analysis of national HIV treatment cascades”. BMJ global health, 2017. 2(2): p. e000227.

6. Schwartz, S.R., et al., HIV viral load monitoring among key populations in low-and middle-income countries: challenges and opportunities. Journal of the International AIDS Society, 2017. 20(S7). 
7. Xing, H., et al., Incidence and associated factors of HIV drug resistance in Chinese HIV-infected patients receiving antiretroviral treatment. PloS one, 2013. 8(4): p. e62408.

8. Maartens, G., C. Celum, and S.R. Lewin, HIV infection: epidemiology, pathogenesis, treatment, and prevention. The Lancet, 2014. 384(9939): p. 258-271.

9. Frehiwot, N., et al., National guidelines for comprehensive HIV prevention, care and treatment. Addis Ababa: Ministry of Health, 2014.

10. Phillips, A., et al., Sustainable HIV treatment in Africa through viral-load-informed differentiated care. Nature, 2015. 528(7580): p. S68-S76.

11. Organization, W.H., Global update on HIV treatment 2013: results, impact and opportunities. 2013.

12. Essajee, S., et al., Reducing mortality in HIV-infected infants and achieving the 90-90-90 target through innovative diagnosis approaches. Journal of the International AIDS Society, 2015. 18(7S6).

13. Levi, J., et al., Can the UNAIDS 90-90-90 target be achieved? A systematic analysis of national HIV treatment cascades. BMJ global health, 2016. 1(2): p. e000010.

14. Lopez, A.D., et al., Global and regional burden of disease and risk factors, 2001: systematic analysis of population health data. The Lancet, 2006. 367(9524): p. 1747-1757.

15. Hoffmann, C.J., J. Maritz, and G.U. Zyl, CD4 count-based failure criteria combined with viral load monitoring may trigger worse switch decisions than viral load monitoring alone. Tropical Medicine \& International Health, 2016. 21(2): p. 219-223.

16. Golin, C.E., et al., A prospective study of predictors of adherence to combination antiretroviral medication. Journal of general internal medicine, 2002. 17(10): p. 756-765.

17. van Praag, E., Planning the incorporation of antiretroviral therapy into comprehensive care programmes. Improving access to care in developing countries, 2002: p. 52.

18. Do, H.M., et al., Factors associated with suboptimal adherence to antiretroviral therapy in Viet Nam: a cross-sectional study using audio computer-assisted self-interview (ACASI). BMC Infectious Diseases, 2013. 13(1): p. 154.

19. Louis, F.J., et al., Virologic outcome among patients receiving antiretroviral therapy at five hospitals in Haiti. PloS one, 2018. 13(1): p. e0192077.

20. Kharsany, A.B. and Q.A. Karim, HIV infection and AIDS in Sub-Saharan Africa: current status, challenges and opportunities. The open AIDS journal, 2016. 10: p. 34.

21. Boulle, A., et al., Seven-year experience of a primary care antiretroviral treatment programme in Khayelitsha, South Africa. Aids, 2010. 24(4): p. 563-572.

22. Hassan, A.S., et al., HIV-1 virologic failure and acquired drug resistance among first-line antiretroviral experienced adults at a rural HIV clinic in coastal Kenya: a cross-sectional study. AIDS research and therapy, 2014. 11(1): p. 9.

23. Zoufaly, A., et al., Prevalence and determinants of virological failure in HIV-infected children on antiretroviral therapy in rural Cameroon: a cross-sectional study. Antivir Ther, 2013. 18(5): p. 681-90.

24. Ayalew, M.B., et al., First-line antiretroviral treatment failure and associated factors in HIV patients at the University of Gondar Teaching Hospital, Gondar, Northwest Ethiopia. HIV/AIDS (Auckland, NZ), 2016. 8: p. 141. 
25. Yayehirad, A.M., et al., Rate of immunological failure and its predictors among patients on highly active antiretroviral therapy at Debremarkos hospital, Northwest Ethiopia: a retrospective follow up study. Journal of AIDS and Clinical Research, 2013. 4(5).

26. Bulage, L., et al., Factors Associated with Virological Non-suppression among HIV-Positive Patients on Antiretroviral Therapy in Uganda, August 2014-July 2015. BMC infectious diseases, 2017. 17(1): p. 326.

27. Degefa, A., et al., Knowledge and attitudes towards antiretroviral therapy among factory workers participating in a cohort on HIV and AIDS, Addis Ababa, Ethiopia. Ethiopian medical journal, 2003. 41: p. 75-87.

28. Rangarajan, S., et al., Factors associated with HIV viral load suppression on antiretroviral therapy in Vietnam. Journal of virus eradication, 2016. 2(2): p. 94.

29. Haile, D., et al., Predictors of Treatment Failure among Adult Antiretroviral Treatment (ART) Clients in Bale Zone Hospitals, South Eastern Ethiopia. PloS one, 2016. 11(10): p. e0164299.

30. Bokretsion GB, Endalkachew N, Getachew KA. HIV/AIDS treatment failure and its determinant factors among first line HAART patients at Felege-Hiwot Referral Hospital, Bahir Dar, Northwest Ethiopia. Journal of AIDS and Clinical Research. 2017;8 (11).

31. Abrams, E.J., et al., Management of HIV/AIDS and co-morbidities in children and adults: cost effectiveness considerations.

32. Bayu, B., et al., Determinants of virological failure among patients on highly active antiretroviral therapy in University of Gondar Referral Hospital, Northwest Ethiopia: a case-control study. HIV/AIDS (Auckland, NZ), 2017. 9: p. 153-159.

33. Kloos, H., et al., Traditional medicine and HIV/AIDS in Ethiopia: Herbal medicine and faith healing: A review. Ethiopian Journal of Health Development, 2013. 27(2): p. 141-155.

34. Kebede, A. and N.T. Wabe, Medication adherence and its determinants among patients on concomitant tuberculosis and antiretroviral therapy in South West Ethiopia. North American journal of medical sciences, 2012. 4(2): p. 67.

35. Hailu GG, Hagos DG, Hagos AK, Wasihun AG, Dejene TA (2018) Virological and immunological failure of HAART and associated risk factors among adults and adolescents in the Tigray region of Northern Ethiopia. PLoS ONE 13 (5): e0196259. https://doi.org/10.1371/journal

36. Abdissa A, Yilma D, Fonager J, Audelin M A, Christensen HL, Mette FO et al. Drug resistance in HIV patients with virological failure or slow virological response to antiretroviral therapy in Ethiopia. BMC Infectious Diseases, 2014; 14:181. https://doi.org/10.1186/1471-2334-14-181 PMID: 24708645

37. Nlend AEN, Lyeb S, Moyo STN and Motaze A N. Viral Monitoring and Prevalence of Viral Failure in HIV-1 Infected Children under First Line Antiretroviral Therapy during the First 60 Months of Treatment in Yaounde', Cameroon: A Serial Cross Sectional Analysis. Open Journal of Pediatrics, 2016; 6:69-74.

38. Jobanputra K, Parker LA, Azih C, Okello V, Maphalala G, Kershberger B et al. Factors Associated with Virological Failure and Suppression after Enhanced Adherence Counselling, in Children, Adolescents and Adults on Antiretroviral Therapy for HIV in Swaziland. PLoS ONE, 2015; 10(2): e0116144. https:// doi.org/10.1371/journal.pone.0116144 PMID: 25695494

39. Singh A, Agarwal A, Chakravarty J, kumari S, Rai M, Sundar S. Predictive Markers of Failure of First Line Anti-Retroviral Treatment in HIV Patients in India. Journal of AIDS and Clinical Research. 2013; 4:210. doi: 
10.4172/2155-6113.1000210

40. Sacamano PL, Farley JE (2016) Behavioral and Other Characteristics Associated with HIV Viral Load in an Outpatient Clinic. PLoS ONE 2016; 11(11): e0166016. doi:10.1371/journal. pone.0166016

41. Yimer YT, Yalew AW. Magnitude and predictors of anti-retroviral treatment (ART) failure in private health facilities in Addis Ababa, Ethiopia. PLoS One. 2015;10(5):e0126026.

42. Aklilu E., Mengistu M., Demeke G., Fekadu A., Hiwot T, Tesfa DH. Evidence that poor HAART adherence has a great impact on HIV/AIDS treatment failure more than severity of illness and opportunity of infection in Ethiopia: Systematic review and meta-analysis. 2018; PROSPERO database (CRD42018100254).

43. Sisay C, Bekele A, Sisay A, Mekonen H, Terfa K. Incidence and Predictors of Anti-Retroviral Treatment (ART) Failure among Adults Receiving HIV Care at Zewditu Memorial Hospital, Addis Ababa, Ethiopia. J AIDS Clin Res. 2017;8(749):2.

44. Okoye AA, Picker LJ. CD 4+ T-cell depletion in HIV infection: mechanisms of immunological failure. Immunological reviews. 2013; 254 (1):54-64.

\section{Figures}




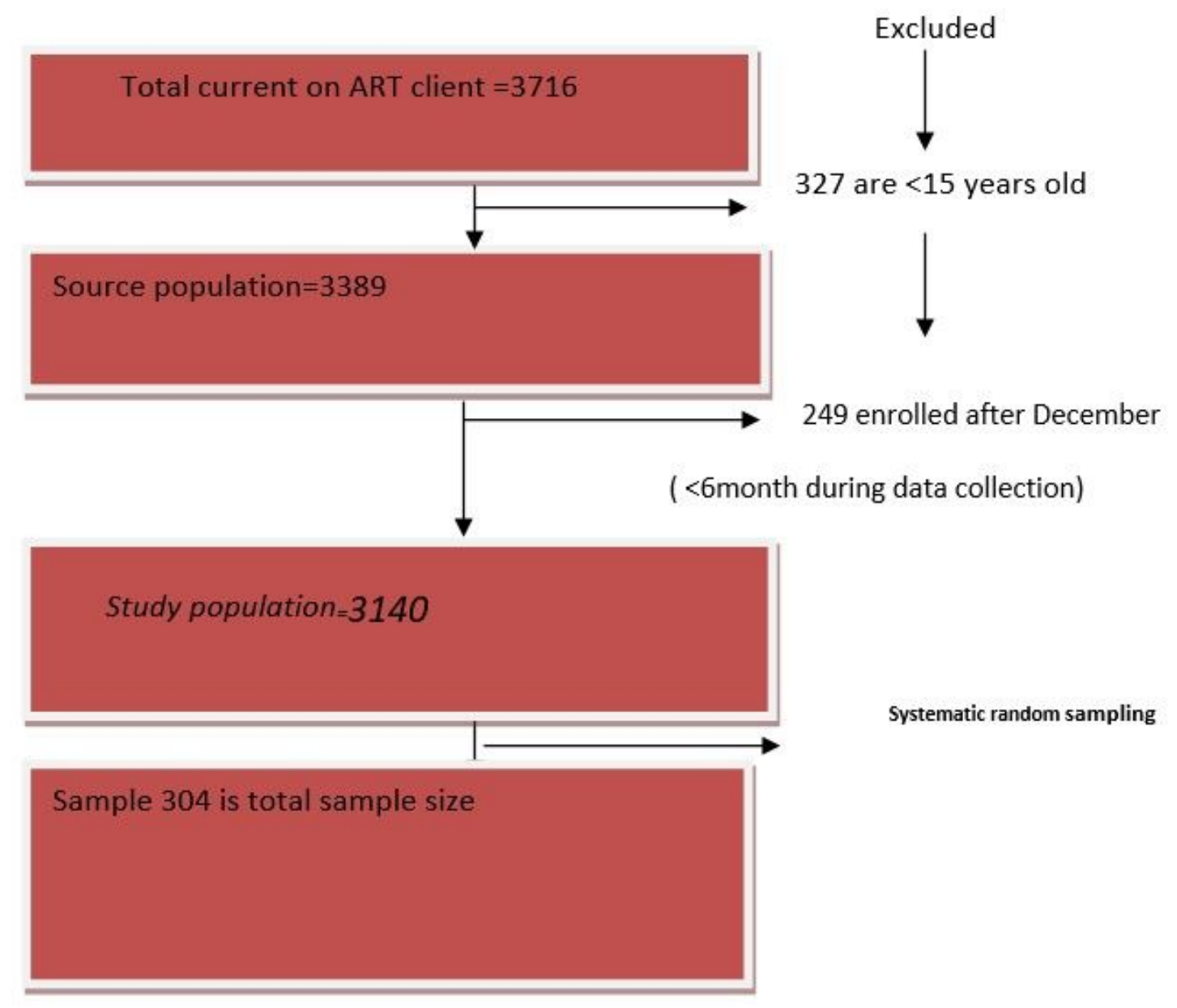

\section{Figure 1}

Schematic diagram that shows sampling procedure for the study of magnitude of virological failure and associated factors among adults on antiretroviral therapy in Debre Markos referral hospital, northwest, Ethiopia, in 2018. 


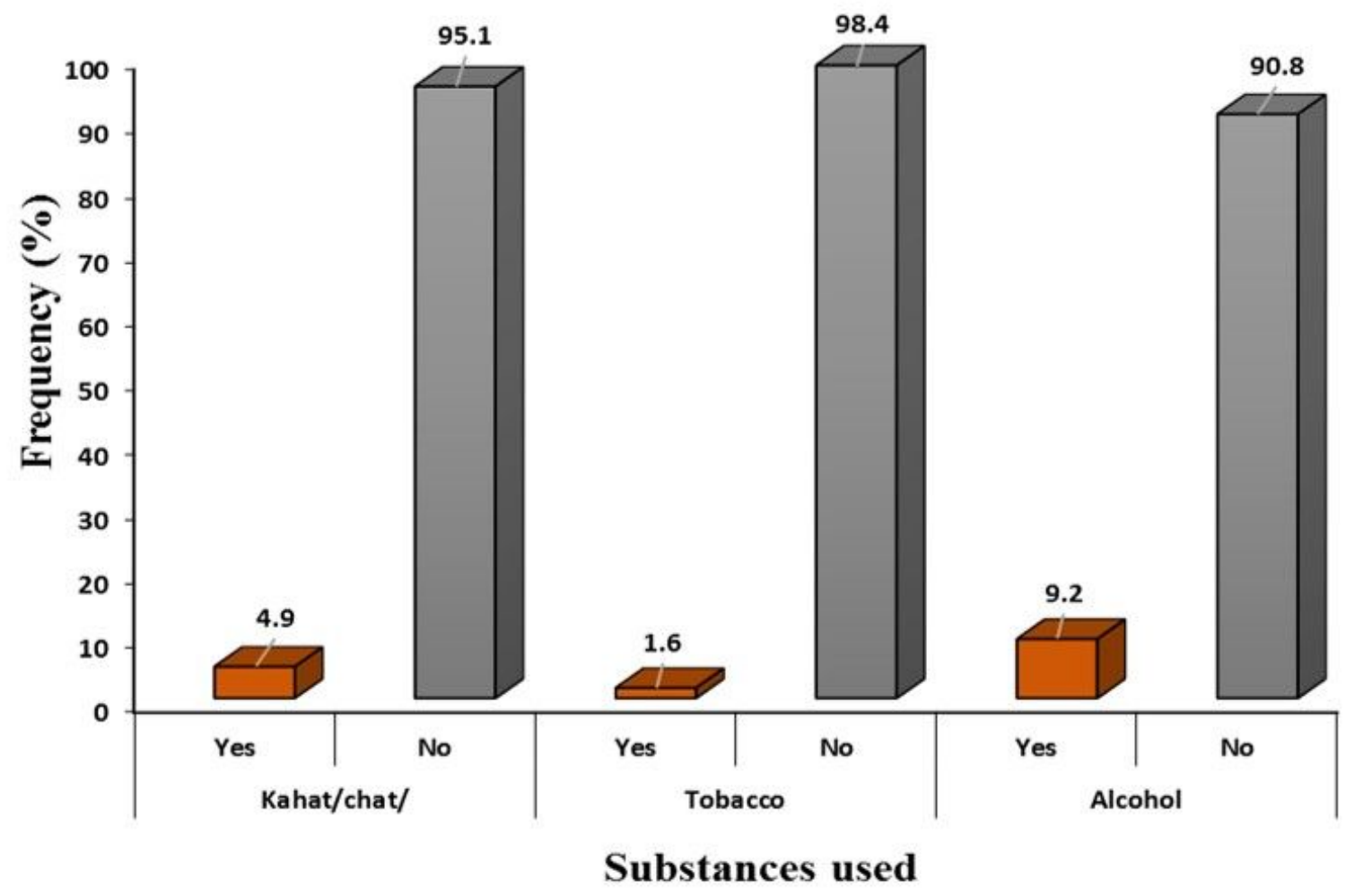

Figure 2

Distribution of substances used among adult patient on ART at Debre Markos Referral Hospital, North West Ethiopia, 2018 


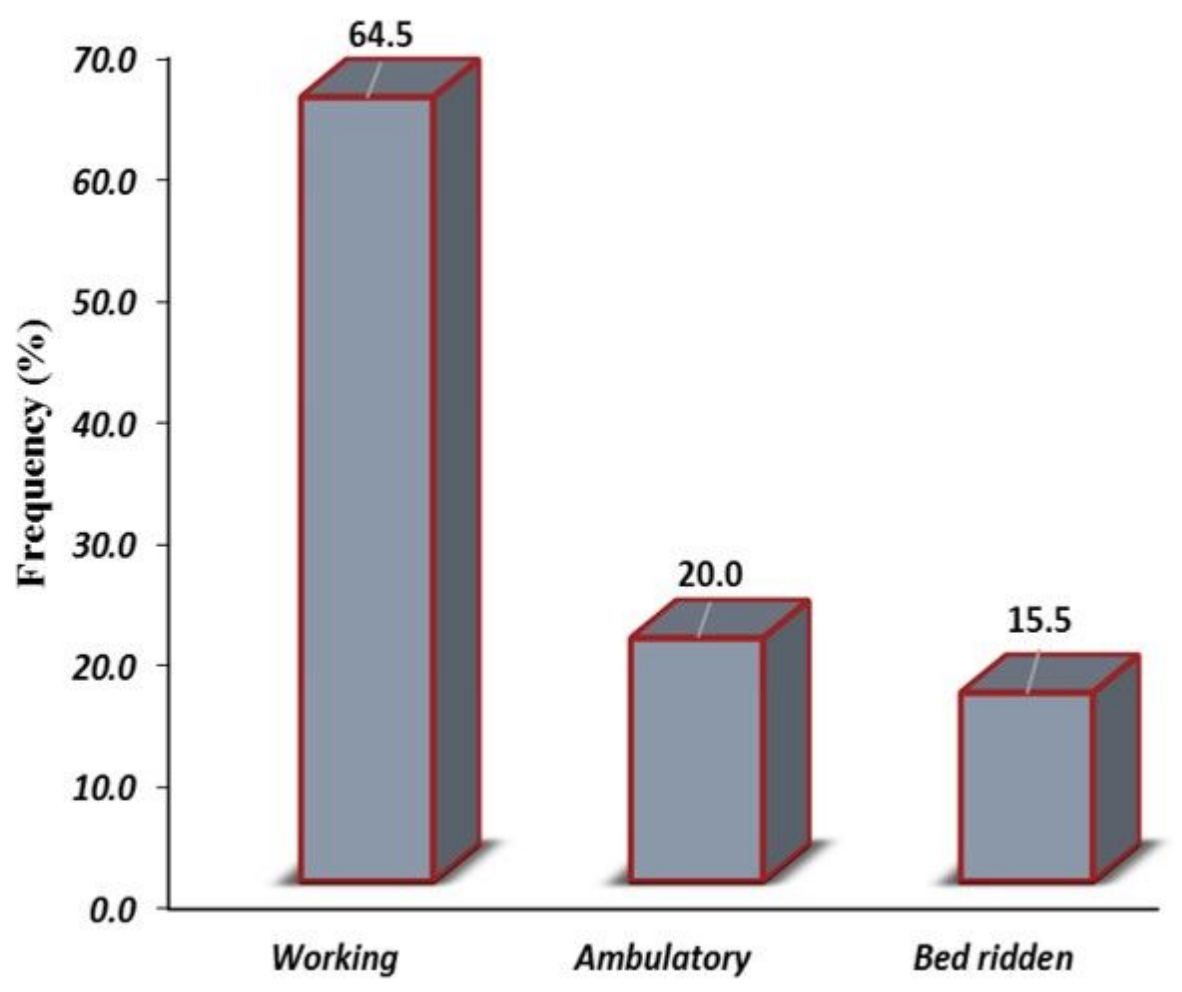

Functioning/working status at baseline

Figure 3

Baseline functioning/working status of adult patient on ART at Debre Markos Referral Hospital, North West Ethiopia, 2018 


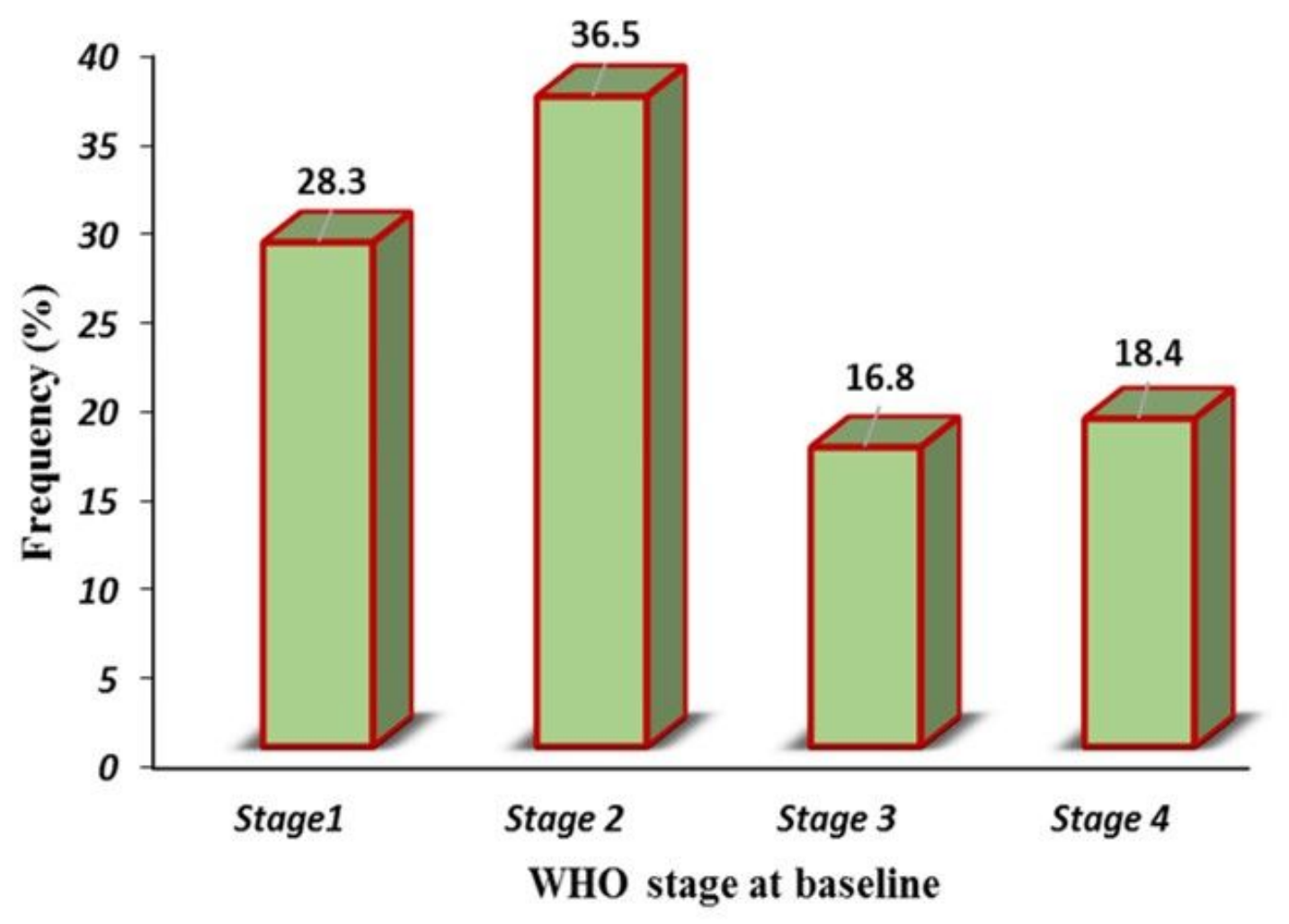

Figure 4

Baseline WHO stage of adult patient on ART at Debre Markos Referral Hospital, North West Ethiopia, 2018 


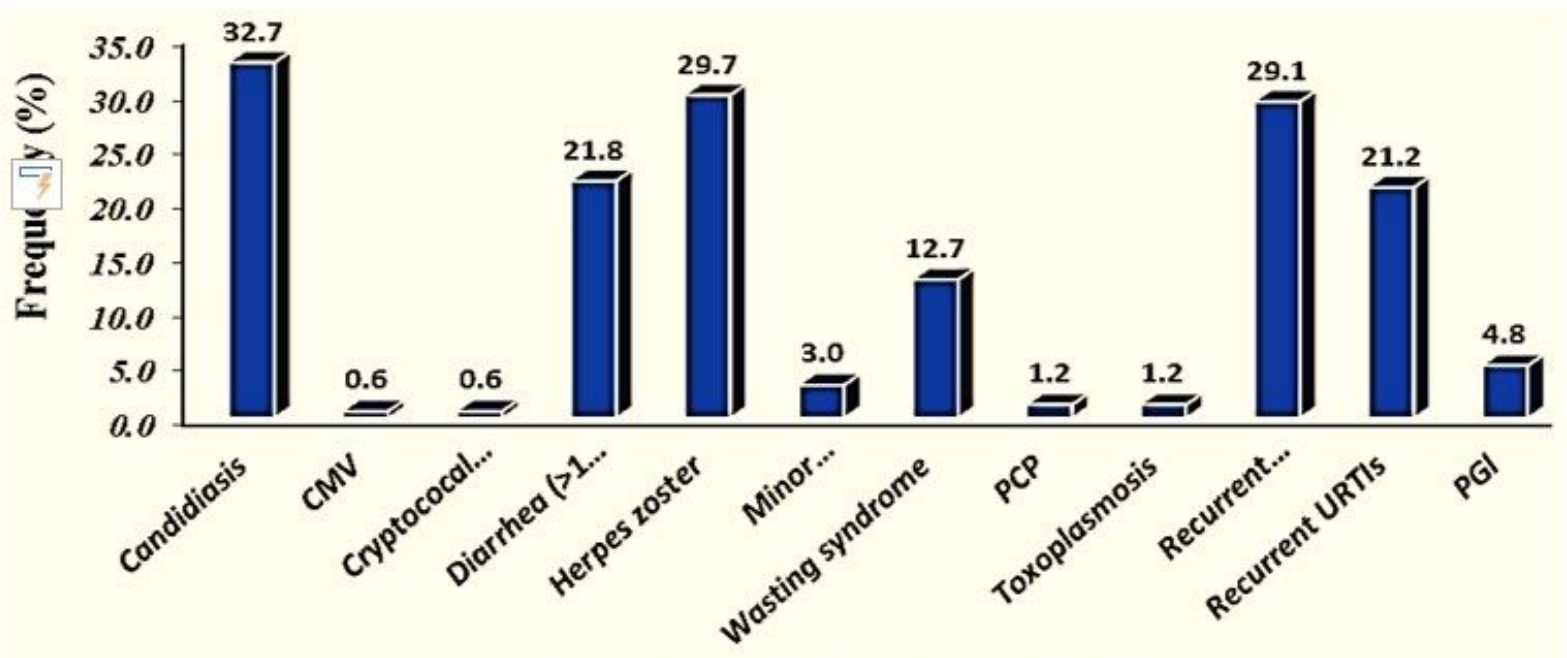

Type of opportunistic infection

Foot note: Because of the possibility of infection by multiple (more than one) opportunistic infections, the percentage exceeded $100 \%$.

Figure 5

Distribution of opportunistic infections among adult patient on ART at Debre Markos Referral Hospital, North West Ethiopia, 2018 


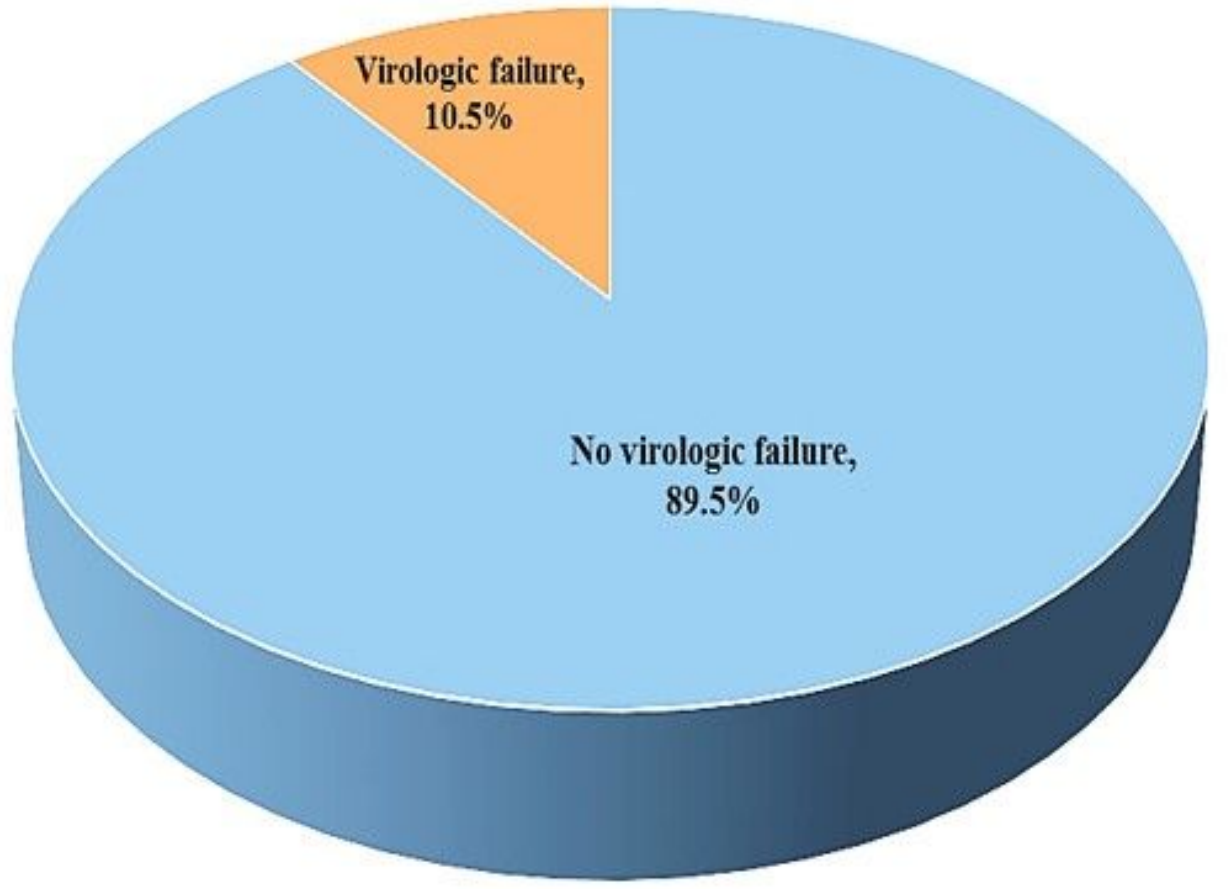

Figure 6

Magnitude of virologic failure among adult patient on ART at Debre Markos Referral Hospital, North West Ethiopia, 2018

\section{Supplementary Files}

This is a list of supplementary files associated with this preprint. Click to download.

- Laboratoryrequisitionandreportform.docx 